\title{
Penerapan AI Melalui Pendekatan Heuristik Semilaritas Pada Game Edukasi Anak Usia Dini
}

\author{
Rendy Jemi Sahputra \& Ari Muzakir \\ Fakultas Teknik Ilmu Komputer, Universitas Bina Darma \\ Email:rjemisahputra@gmail.com
}

\begin{abstract}
Game is one of the rapidly growing industries in everyday life. Currently the game is very popular in all circles, both among children, teenagers and adults. However, there are still many games that only prioritize addictive elements and ignore educational elements. Therefore, here the author will build a game that has an educational element as a learning medium. This study will apply AI to an early childhood educational game through a heuristic semilarity approach to the habits of early childhood in answering questions such as equating in everyday life. This research will produce a game that can improve intelligence, creativity and memory at an early age such as guessing pictures, counting and arranging words randomly.
\end{abstract}

Keywords: Educational Games, Early Childhood Education

\section{Pendahuluan}

Perubahan teknologi informasi saat ini berkembang sangatlah maju, banyak penemuan yang diciptakan berbasis teknologi tersebut sangat bermanfaat bagi kehidupan manusia khususnya pada penggunaan aplikasi berbasis game. Game edukasi berbasis simulasi didesain untuk mensimulasikan permasalahan yang adasehingga diperoleh esensi atau ilmu yang dapat digunakan untuk menyelesaikan permasalahan tersebut. Game simulasi dengan tujuan edukasi ini dapat digunakan sebagai salah satu media edukasi yang memiliki pola pembelajaran learning by doing.

Berdasarkan pola yang dimiliki oleh game tersebut, pemain dituntut untuk belajar sehingga dapat menyelesaikan permasalahan yang ada. Seiring dengan tantangan dalam menciptakan generasi yang berkualitas, pendidikan harus dilakukan sejak usia dini dalam hal ini melalui Pendidikan Anak Usia Dini(PAUD), di PAUD anak sudah diajarkan cara belajar dengan media bermain (Vitianingsih, 2016). Game edukasi adalah permainan yang disertai pembelajarandan merupakan media pembelajaran terbaru yang diharapkan dapat meningkatkan pemahaman dengan cepat karena didukung permainan yang menarik dan membuat siswa menjadi aktif (Hilaliyah et al., 2017).

Dalam pembuatan game, pasti memerlukan suatu perancangan yang sesuaidengan tujuan pembuat. Khususnya untuk game edukasi, tujuan yang dimaksud ialah bagaimana membuat pengguna menjadi lebih mengerti mengenai suatuwawasan atau pembelajaran ketika sedang atau telah bermain.

Game AI merupakan game yang mengubah metode, proses, dan algoritma pada kecerdasaan tersebut yang akan di aplikasikan ke pembuatan danpengembangan game. Dalam hal ini, adanya kecerdasan buatan atau AI merupakan salah satu unsur yang diperlukan dalam pembentukan game khususnyagame edukasi oleh sebab itu penelitian ini diperlukan untuk membuat dan menganalisa metode kecerdasaan yang baik untuk sebuah game dengan melalui pendekatan heruistik semliratas pada sebuah game edukasi anak usia dini. Dari uraian diatas menunjukkan bahwa penggunaan kecerdasan buatan di dalam game dibutuhkan untuk meningkatkan tantangan di dalam game. Membuat game 
menjadi lebih dinamis dan dapat menunjang realitas game, sehingga akan menciptakan kesenangan bagi pengguna pada saat memainkan game dan ketertarikan pengguna untuk memainkan game juga akan meningkat (Abdi et al., 2017). Anak usia dini sangat membutuhkan pola atau cara belajar yang menarik dimana dengan memanfaatkan teknologi yang ada saat ini dapat membuat mereka berfikir bahwa belajar adalah suatukegiatan yang menyenangkan karena mereka dapat bermain sekaligus belajar (Jayanti et al., 2018). Maka dari itu penulisbertujuan membuat ingin membuat sebuah game edukasi anak usia dini yang diharapkan agar mempermudah dalam proses pembelajaran bagi guru pendikan anak usia dini (PAUD) dengan judul penelitian yaitu Penerapan Artificial Intelligence Melalui Pendekatan Heuristik Similaritas Pada Game Edukasi Anak Usia Dini.

\section{Tinjauan Literatur}

\subsection{Gamification}

Gamification adalah pendekatan pembelajaran menggunakan elemen-elemen di dalam game atau video game dengan tujuan memotivasi para siswa dalam proses pembelajaran dan memaksimalkan perasaan enjoy dan engagement terhadap proses pembelajaran tersebut,selain itu media ini dapat digunakan untuk menangkap hal-hal yang menarik minat siswa dan menginspirasinya untuk terus melakukan pembelajaran. Gamifikasi adalah menggunakan unsur mekanik game untuk memberikan solusi praktikal dengan cara membangun ketertarikan(engagement) kelompok tertentu (Jusuf, 2016).

\subsection{Pengertian Kecerdasan Buatan}

Kecerdasan buatan yang biasa disingkat AI (Artificial Intelligence) merupakan ilmu tentang bagaimana membangun suatu sistem komputer yang menunjukkan kecerdasan dalam berbagai cara. AI merupakan area penelitian yang dinamis dalam topik riset ilmu komputer. Sampai saat ini, telah banyak penelitian mengenai perkembangan AI diantaranya neural network, evolutionary computing,machine learning, natural language processing, dan object oriented programming. Kenyataannya, saat ini banyak game yang membangun AI untuk meningkatkan ketertarikan pengguna. Sehingga adanya AI merupakan salah satu faktor penting yang harus ada dalam game. (Yunanto et al., 2017)

\subsection{Heuristik}

Setiap manusia di dunia secara umum pasti memiliki kebiasaan dan tingkah laku yang sama seperti makan, minum, jalan, dan sebagainya walaupun tidak sama persis. Selain itu manusia memiliki kebiasaan buruk yaitu mudah lupa. Menurut penelitian Scientific American tahun 2008, manusia memiliki dua sistem memori dalam pikiran manusia yakni short-term dan long-term. Dua sistem ingatan tersebut memiliki peran masing-masing dalam mengingat sesuatu. Sehingga tidaksemua hal atau ingatan bisa dimasukkan dalam long-term yang menyebabkan manusia dapat lupa. Menurut penelitian dari Thalheimer, manusia akan lupa $0 \%$ sampai $94 \%$ terhadap apa yang mereka pelajari tergantung kondisi mereka. Dia juga menyebutkan manusia akan lupa 0\%-74\% dalam satu sampai dua hari.

Manusia memiliki cara tersendiri untuk mengatasi lupa. Manusia biasanyamudah ingat terhadap pembelajaran yang menggunakan contoh dan praktek.Contoh kasus, pelajar sering lupa terhadap pelajaran yang teoritis. Pelajar yang lupa materi akan kesulitan dalam mengerjakan soal. Secara umum, salah satu cara pelajar dalam mengatasi kelupaan tersebut ialah dengan mengingat-ingat contoh dikehidupan sehari-hari mereka. Kemudian contoh tersebut dikait-kaitkan dengansoal yang ada. Sehingga terbentuklah suatu aturan 
yang mempengaruhi keputusandalam menjawab soal. Aturan keputusan ini dapat disebut dengan heuristik. Serta metode yang digunakan ini dapat disebut dengan heuristik similaritas. (Yunanto et al., 2017).

\subsection{Algoritma Similaritas Teks dan Evaluasi}

Similaritas adalah salah satu bagian penting dalam pembangunan suatu heuristik (Read et al., 2011). Perhitungan similaritas juga merupakan salah satu tahapan yang digunakan pada teknik data mining. Han et al., (2006) juga menjelaskan dalam bukunya juga menunjukkan persamaan-persamaan mengenai nilai similaritas atau jarak kedekatan yang sering digunakan dalam proses klustering, prediksi, dan klasifikasi.

Selain itu, Gomaa et al., (2013) menjelaskan mengenai similaritas untuk kasus data teks. Dia menjelaskan terdapat bebrapa persamaan untuk menghitung nilai similaritas diantaranya Simple Matching Coefficient (SMC) (1), Jaccard Coefficient (2), dan Rao's Coefficient (3) dengan acuan seperti Rumus 1.

Rumus 2.1. Algoritma similaritas untuk kasus data teks

\begin{tabular}{|cc|cc|}
\hline & $\mathbf{x}^{(j)}$ & \\
& & 1 & 0 \\
\hline $\mathbf{x}^{(i)}$ & 1 & $\mathrm{a}$ & $\mathrm{b}$ \\
& 0 & $\mathrm{c}$ & $\mathrm{d}$ \\
\hline
\end{tabular}

$S_{s m c}\left(x^{(i)}, x^{(j)}\right)=\frac{a+d}{n}$
$S_{j c}\left(x^{(i)}, x^{(j)}\right)=\frac{a}{a+b+c}$
$S_{r c}\left(x^{(i)}, x^{(j)}\right)=\frac{a}{n}$

\subsection{Rumus Algoritma Persamaan Evaluasi}

Dalam information retrieval, evaluasi yang sering digunakan ialah mengenai evaluasi performa dan efisiensi. Evaluasi performa ialah evaluasi yang menunjukkan tingkat keakuratan metode. Sedangkan evaluasi eficiensi menunjukkan tingkat kecepatan atau kompleksitas metode. Evaluasi yang seringdigunakan ialah menggunakan perhitungan akurasi yang dijelaskan pada Tabel 1dan persamaan di gambar 2 (Manning et al., 2009). Sehingga akurasi merupakanperhitungan dari hasil data yang benar dibagi dengan semua data.

Tabel 2.1 Label evaluasi performa

\begin{tabular}{clcc}
\hline & & \multicolumn{2}{c}{ Kelas Prediksi } \\
& & Positif & Negatif \\
\hline \multirow{2}{*}{ Kelas Aktual } & Positif & TP & FN \\
& Negatif & FP & TN \\
\hline
\end{tabular}


Metode similaritas pada information retrieval juga memiliki pendekatan lain dalam proses komparasinya yang disebut rangkaian n-gram (Jurafsky \& Martin, 2014). N-gram biasa digunakan untuk kasus markov model dimana n-gram digunakan untuk komparasi fitur yang memiliki dependensi melalui pendekatan statistik. N-gram yang sering digunakan dalam komparasi ialah unigram, bigram, dan trigram. Semakin tinggi jumlah $\mathrm{n}$, maka semakin tinggi pula kompleksitasnya.Persamaan umum n-gram dituliskan pada persamaan pada gambar 3 dimana $\mathrm{S}$ adalah vector yang berisi fitur kumpulan term atau kata. Perbedaan unigram, bigram, dan trigram terletak pada jumlah $\mathrm{n}$ dimana unigram memiliki jumlah $n$ sama dengan satu, bigram memiliki jumlah $n$ sama dengan dua, dan trigram memiliki jumlah $n$ sama dengan tiga.

$$
S=k_{1}, k_{1}, \ldots, k_{r}(5) \quad P_{n}(S)=\prod_{i=1}^{r} P\left(k_{i} \mid k_{i-1}, k_{i-2}, \ldots, k_{i-(n-1)}\right)
$$

Rumus 2.2. Algoritma persamaan komparasi

\subsection{Implementasi Game Edukasi Pada Pembelajaran Anak}

Media pembelajaran seperti game edukasi merupakan game yang khusus dirancang untuk mengajarkan user suatu pembelajaran tertentu, pengembsangan konsep, pemahaman dan membimbing user dalam melatih kemampuan, mengaktifkan indra serta memotivasi untuk memainkannya. Pada pembelajaryang dilakukan pada Taman Kanak-kanak (TK) mayoritas anak-anak belajardalam mengenal huruf, angka dan warna. Untuk membantu menumbuhkan minat belajar anak dalam mengenal huruf, angka dan warna dibutuhkan media pembelajaran yang menyenangkan. Penggunaan program pendidikan berbasis multimedia yang menggabukan antara suara berbentuk digital, gambar warna- warni dan animasi pendukung akan membuat menarik dan menyenangkan bagi anak. (Borman \& Erma, 2018). 


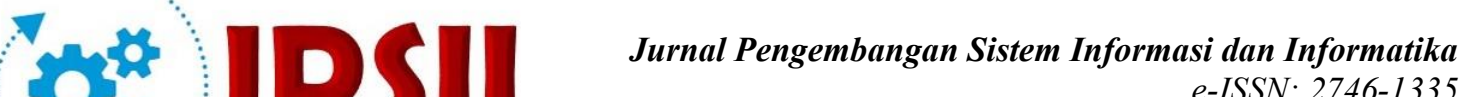

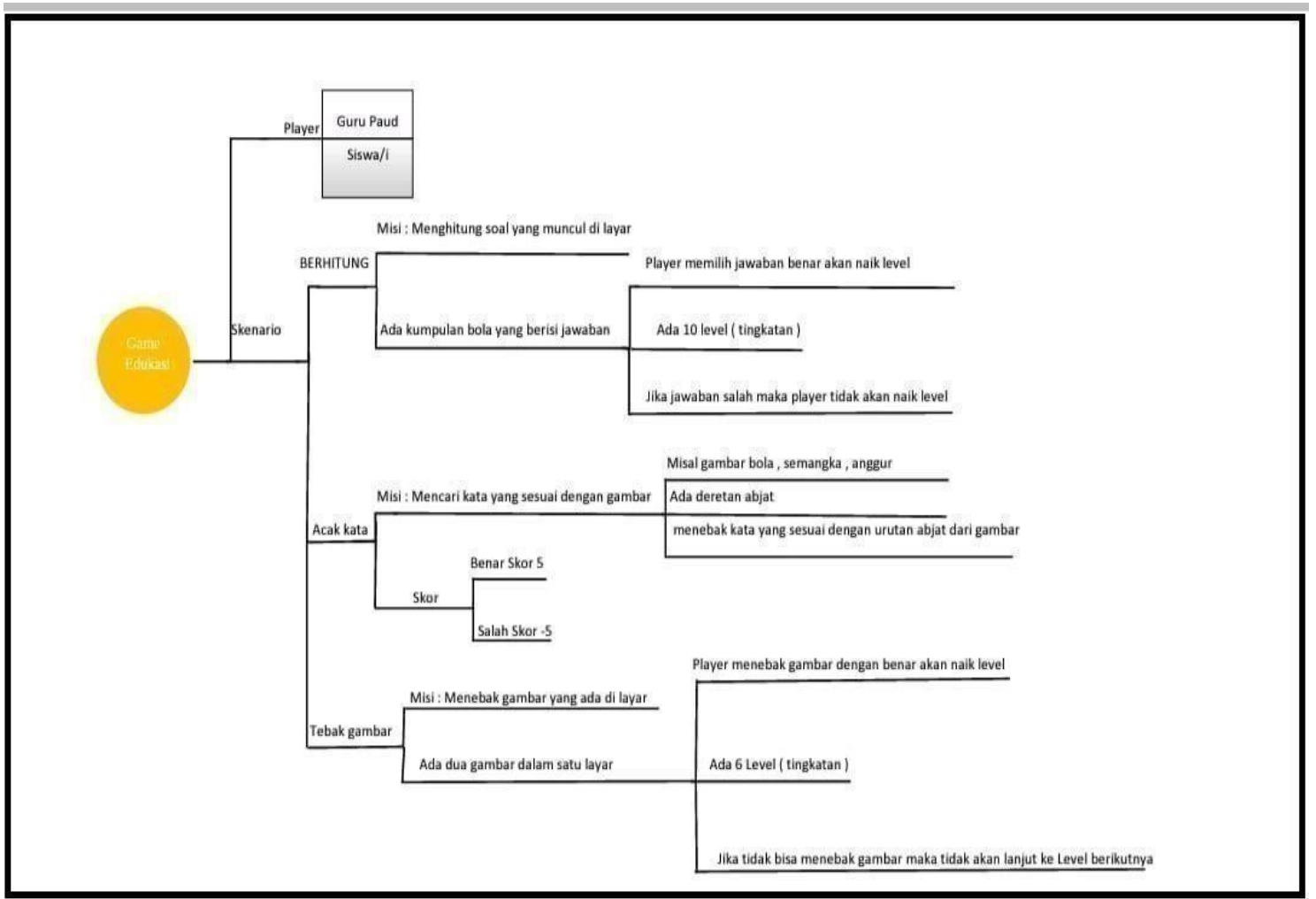

Gambar 2.1 Skenario game edukasi

Penelitian berjudul Kecerdasan Buatan Pada Game Edukasi Untuk Pembelajaran Bahasa Inggris Berbasis Pendekatan Heuristik Similaritas (Yunanto dkk, 2017). Game menjadi salah satu industri yang berkembang pesat pada kehidupan sehari-hari. Saat ini game sangatlah popular di semua kalangan baik kalangan anak-anak, remaja maupun dewasa. Namun masih banyak game yang hanya memprioritaskan unsur adiktif dan mengabaikan unsur edukatif. Selain itu, banyak game berbasis pendidikan yang kurang memiliki unsur fun. Oleh karena itu, diperlukan game yang memiliki unsur edukasi dan fun sebagai media hiburan dan pendidikan bagi pengguna. Game edukasi yang bermanfaat di era globalisasi ini ialah tentang game edukasi Bahasa Inggris. Dalam pembangunan game dibutuhkan rancangan teori yang disebut gamification dimana salah satu elemen penting yang harus ada di dalam game ialah peran dari kecerdasan buatan dimana sering disebut AI (Artificial intelligence). Penelitian ini bertujuan untuk membangun AI pada game edukasi Bahasa Inggris yang cepat dan akurat. Metode yang digunakan pada AI ialah berbasis pada pendekatan heuristik terhadap kebiasaan manusia dalam menjawab soal seperti menyamakan soal dengan ingatannya pada kejadian sehari-hari. Sehingga pada AI diperlukan suatu persamaan untuk menghitung similaritas antara data di soal dan database. Hasil penelitian menunjukkan bahwa game dapat berjalan dengan lancar pada platform desktop dan android. Hasil metode AI yang diterapkan juga mendapatkan nilai akurasi yang tinggi yakni $85 \%$ dan memiliki tingkat kecepatan yang baik yakni rata-rata sekitar 12-16 milidetik. Sehingga metode pendekatan heuristiksimilaritas merupakan metode yang cukup menjanjikan ketika diimplementasikan pada kecerdasan buatan di game edukasi Bahasa Inggris untuk menjawab soal secara otomatis.

Penelitian berjudul Prototype Game Edukasi Materi Sains Menggunakan Pendekatan

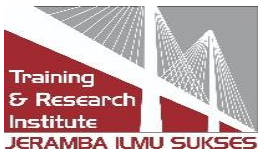


Kontekstual Di Smp Negeri 4 Banjarbaru (Pahmawati dkk, 2021).Teknologi pada jaman sekarang terus berkembang, saat ini teknologi bukan hanya digunakan oleh orang dewasa tetapi juga oleh anak-anak. Saat ini yang paling diminati oleh anak-anak adalah game berbasis game aksi. Ada juga game untuk pembelajaran, yaitu game edukasi, game edukasi merupakan salahsatu media pembelajaran yang interaktif dalam menampilkan keterampilan dan kegiatan belajar siswa. Game edukasi ini merupakan sebuah rancangan atau prototype pembelajaran untuk siswa di SMP Negeri 4 Banjarbaru yang berisi tentang materi pelajaran sains, berupa matematika, biologi, kimia, dan fisika. Melalui pendektan kontekstual diharapkan agar siswa mampu meningkatkan kemampuan pemahaman dan pemecahan masalah secara sistematis. Metode pengumpulan data yang digunakan berupa Unified Modeling Language (UML). Perancangan game edukasi menggunakan tools Unity 3D dan berbahsa pemograman C\#. Pengujian aplikasi dilakukan agar dapat menemukan kekurangan dalam aplikasi. Melalui Studi ini dapat diperoleh data ataupun informasi dengan mengumpulkan dan mempelajari berbagai referensi dari buku maupun internet. Maka penelitian ini dapat menghasilkan sebuah rancangan game edukasi agar dapat memudahkan siswadalam pembelajaran sains

\section{Metode Penelitian}

\subsection{Metode Pengumpulan Data}

Metode yang digunakan dalam pengumpulan data sebagai berikut:

1) Studi literature yang diperoleh dari jurnal-jurnal online, e-book dan buku-buku yang sesuai dengan permasalahan yang berhubungan dengan objek.

2) Interview (wawancara), yaitu proses tanya jawab kepada pengajar atau guru pada Tk Negeri Pembina untuk mendapatkan informasi yang dibutuhkan.

3) Observasi, pengumpulan data dikumpulkan secara langsung kepada Tk Negeri Pembina untuk melihat sistem yang berjalan dan mencatat hasil observasi untuk menentukan proses yang akan berjalan kedepanya.

\subsection{Metode Pengembangan Aplikasi}

Ada berbagai metode dalam pengembangan aplikasi salah satunya adalah Waterfall, Metode penulis aplikasi yang digunakan dalam pengembangan adalah Waterfall. Pada metode ini memiliki tahapan dari tahapan analisis kebutuhan hingga tahapan pemeliharanan. Tahapan - Tahapan daru metode waterfall yaitu sebagai berikut:

1) Requierement Analisis

Tahap ini pengembang sistem diperlukan komunikasi yang bertujuan untuk memahami perangkat lunak yang diharapkan oleh pengguna dan batasan perangkat tersebut. Informasi inibiasanya diperoleh melalui wawancara, diskusi atau survei langsung. Informasi dianalisis untuk mendapatkan data yang dibutuhkan oleh pengguna.

2) System Design

Spesifikasi kebutuhan dari tahap sebelumnya akan dipelajari dalam fase ini dan desain sistem disiapkan. Desain Sistem membantu dalam menentukan perangkat keras (hardware) dan sistem persyaratan dan juga membantu dalam mendefinisikan arsitektur sistem secara keseluruhan.

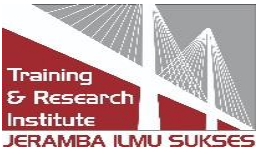




\section{3) Implementation}

Pada tahap ini, sistem pertama kali dikembangkan di program kecil yang disebut unit, yang terintegrasi dalam tahap selanjutnya. Setiap unit dikembangkan dan diuji untuk fungsionalitas yang disebut sebagai unit testing.

4) Intergration \& Testing

Pada tahap ini, akan dilakukan uji coba game pada 10 anak dan melihat persepsi mereka terhadap usability dari game tersebut dengan menggunakan kuesioner system usability scale (sus) dan melihat hasil tanggapan mereka terhadap game.

5) Operation \& Maintenance

Tahap akhir dalam model waterfall. Perangkat lunak yang sudah jadi, dijalankan serta dilakukan pemeliharaan. Pemeliharaan termasuk dalam memperbaiki kesalahan yang tidak ditemukan pada langkah sebelumnya. Perbaikan implementasi unit sistem dan peningkatan jasa sistem sebagai kebutuhan baru.

\section{Hasil dan Pembahasan}

\subsection{Halaman Utama}

Halaman menu utama pada gambar 1, adalah (Splash Screen) terlebih dahulu yang menggambarkan tema aplikasi dan menu selamat datang atau tampilan awal pada aplikasi game PAUD TK Negeri Pembina Sekolah Ramah Anak. Halaman ini adalah halaman pertama kali muncul ketika aplikasi dibuka. Halaman ini juga akan secara otomatis mengarahkan ke halaman Login, dengan waktu yang sudah di set di dalam aplikasi (coding) selama 3 detik.
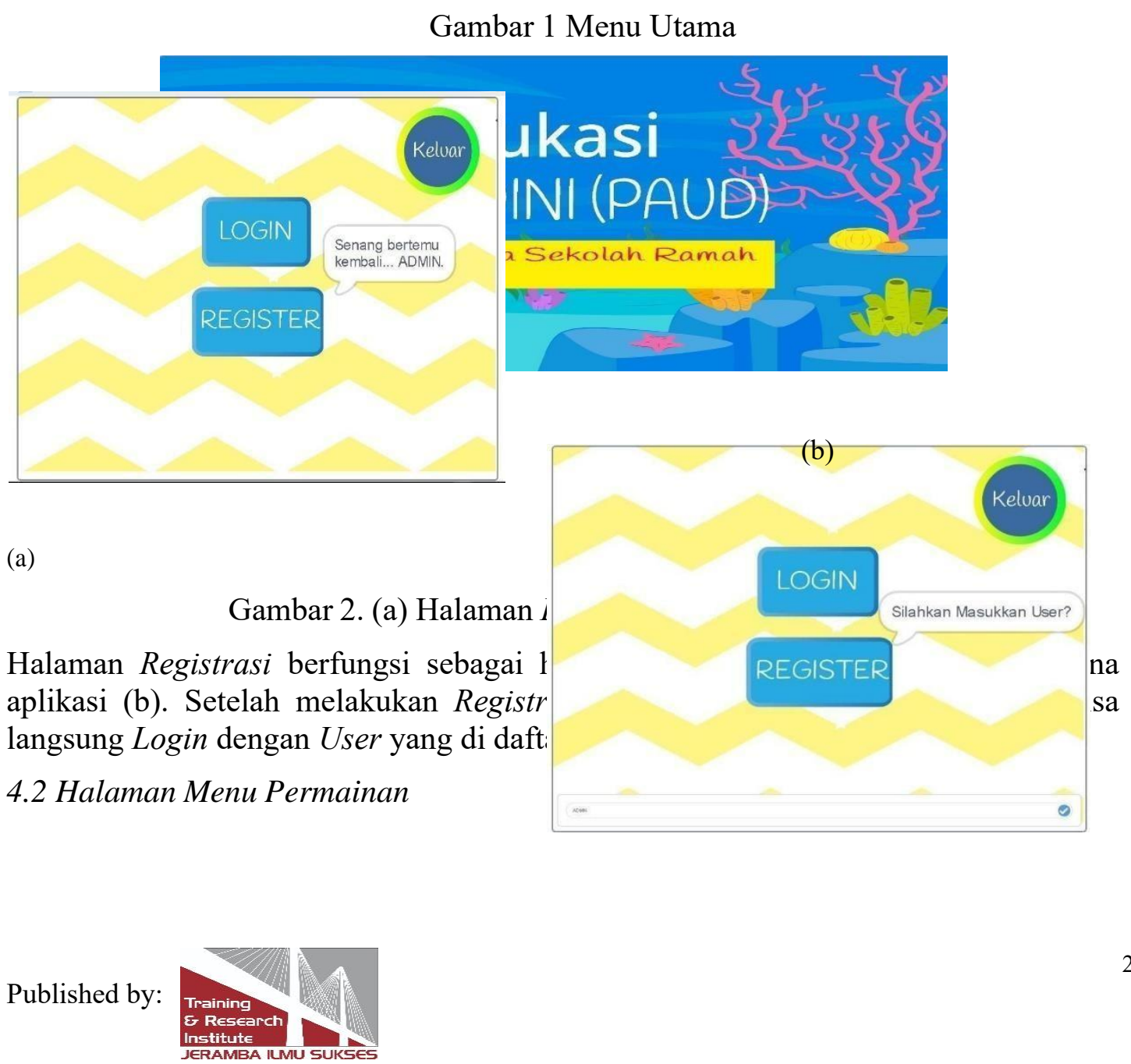
Setalah login maka pengguna akan di tampilkan pada halaman menu permainan yang meliputi berhitung, tebak gambar dan acak kata.

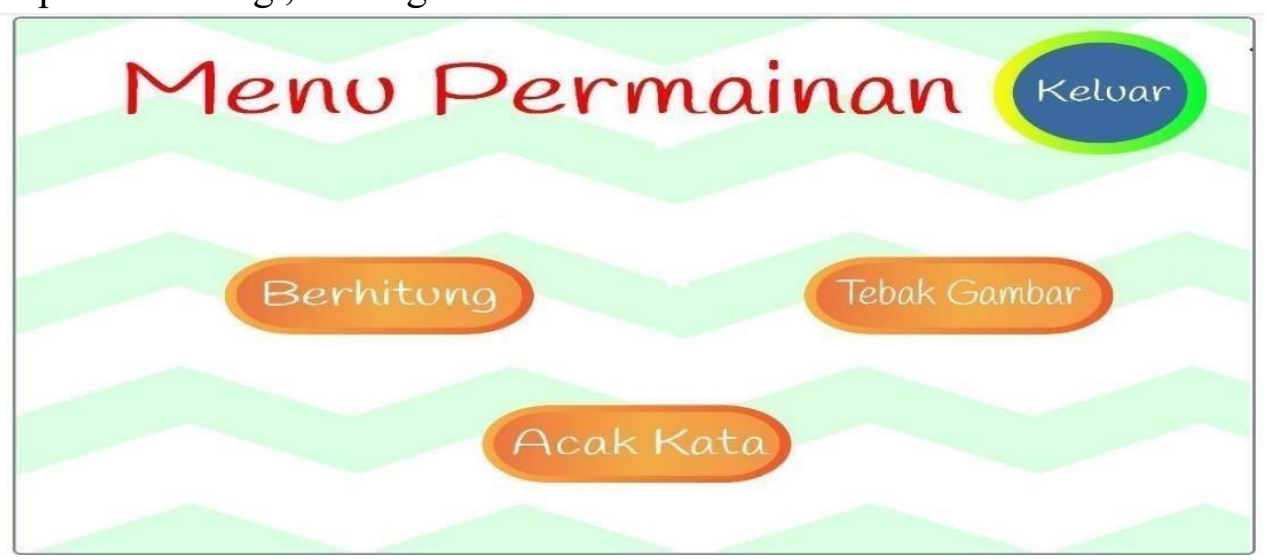

\section{Gambar 3. Menu Permainan}

\subsection{Halaman Menu Berhitung}

Pada menu berhitung ini anak-anak PAUD diminta untuk menjawab penjumlahan yang diberikan oleh soal. Anak-anak PAUD cukup memilih jawaban dengan mengklik tombol angka 8 atau 5. Jika jawaban benar, maka akan muncul notifikasi yang menunjukkan jawaban benar dan salah, jika jawaban benar maka akan mendapatkan skor 20 jika jawaban salah makan skor tidak akan bertambah, seperti yang ditunjukkan pada gambar 4 (a) dan (b).

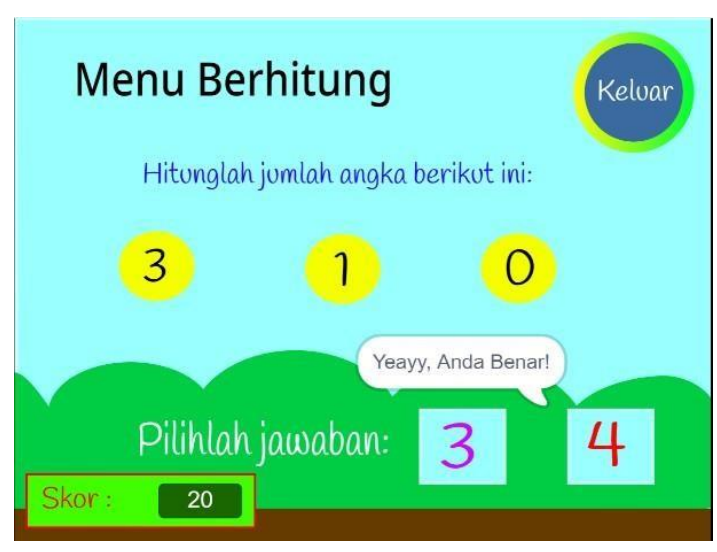

(a)

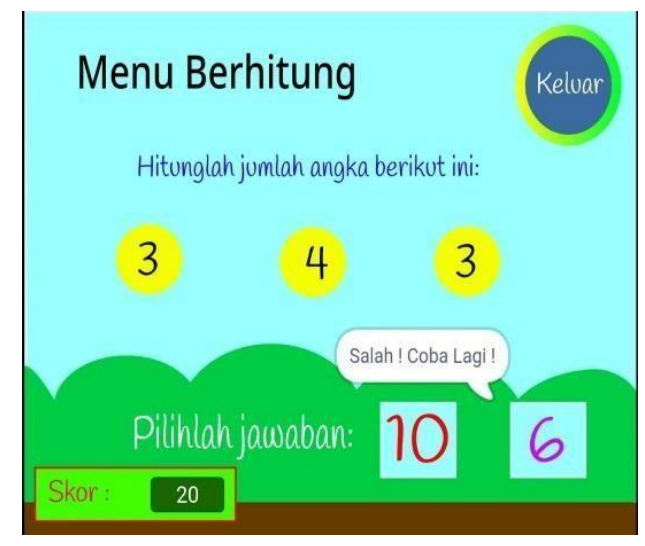

(b)

Gambar 4. (a) Jawaban Benar ; (b) Jawaban Salah

\subsection{Halaman Menu Tebak Gambar}

penulis membuat halaman menu permainan dengan kategori tebak gambar, dimana pada menu ini terdapat game menentukan objek apa pada gambar dengan melihat potongan- potongan gambar yang ada pada menu. Jika jawaban benar, maka akan muncul notifikasi yang menunjukkan jawaban benar dan salah, jika jawaban benar maka akan mendapatkan skor 25 jika jawaban salah makan skor tidak akan bertambah, seperti yang ditunjukkan pada gambar 5

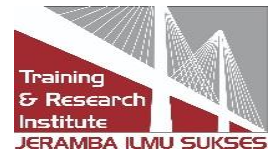


(b)

dan (b).

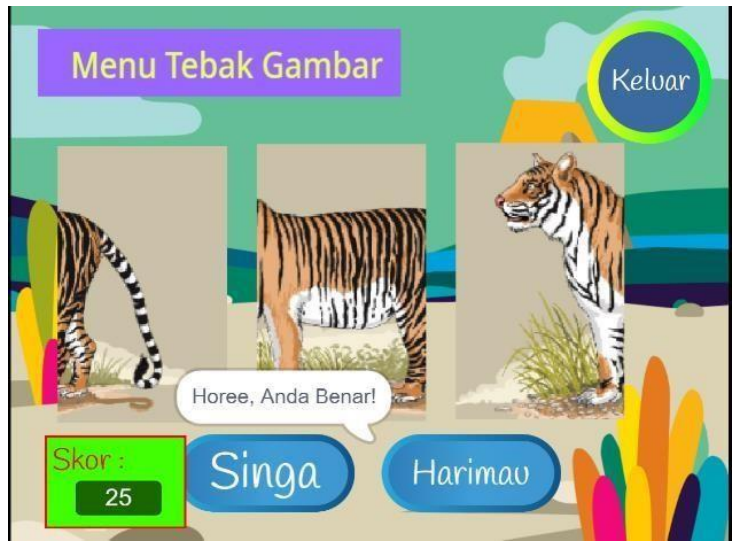

(a)

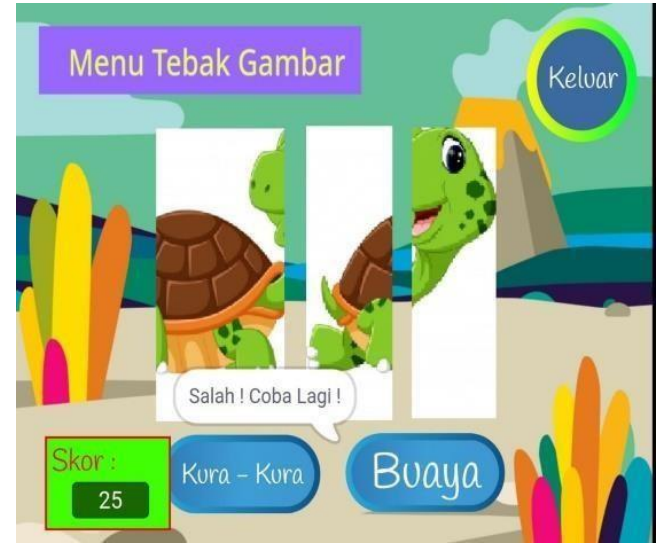

(b)

Gambar 5. (a) Jawaban Benar; (b) Jawaban Salah

\subsection{Halaman Menu Acak Kata}

Pada halaman ini penulis membuat halaman menu permainan dengan kategori acak kata, dimana pada menu ini terdapat game menentukan kata apa berdasarkan susunan pada gambar dan panduan kata yang muncul dengan melihat petunjuk gambar yang ada pada menu. Jika jawaban benar, maka akan muncul notifikasi yang menunjukkan jawaban benar dan salah, jika jawaban benar maka akan mendapatkan skor 25 jika jawaban salah makan skor tidak akan bertambah, seperti yang ditunjukkan pada gambar 5 (a) dan (b).

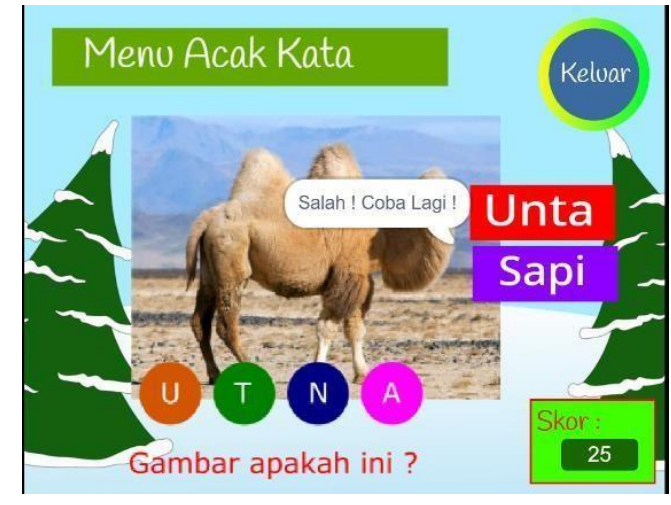

(c)

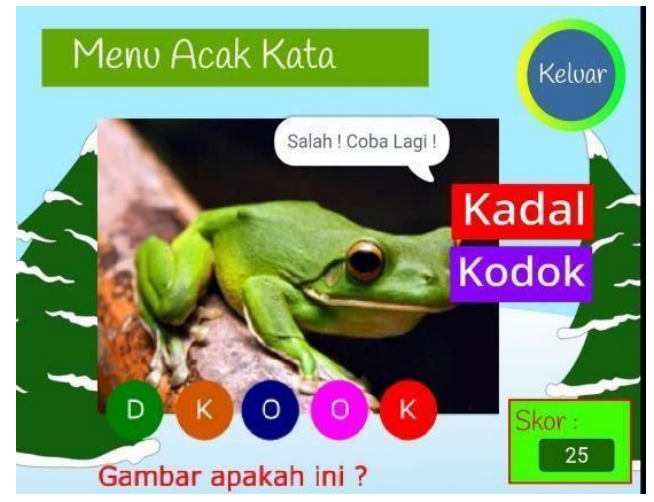

(b)

Gambar 6. (a) Jawaban Benar ; (b) Jawaban Salah

\section{Kesimpulan}

Berdasarkan pada pembahasan yang di jelaskan pada bab-bab sebelumnya maka dapat diTarik kesimpulan sebagai berikut:

1) Dengan adanya aplikasi game anak PAUD pada TK Negeri Pembina Sekolah

Published by:

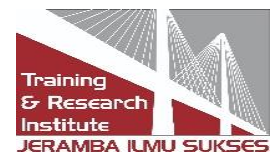


Ramah Anak maka dapat membantu dan memberikan manfaat bagi pengguna maupun bagi guru sehingga dapat menjadi alternatif pembelajaran untuk anak usia dini (PAUD) dan proses pembelajaran dapatberjalan dengan efektif dan efisien dengan optimal pada anak-anak PAUD.

2) Aplikasi game anak PAUD pada TK NegeriPembina Sekolah Ramah Anak ini berisi materi pembelajaran dasar yang di sesuaikan dengan kebutuhan Anak Usia Dini seperti angka , gambar dan hewan sehingga dapat membantu Anak Usia Dini untuk mengenal benda dan mahluk yang ada di sekitarnya.

\section{Referensi}

Abdi, M., Herumurti, D., \& Kuswardayan, I. (2017). Analisis Perbandingan Kecerdasan Buatan padaComputer Player dalam Mengambil Keputusan pada Game Battle RPG. JUTI: Jurnal Ilmiah Teknologi Informasi, 15(2), 226. https://doi.org/10.12962/j24068535.v15i2.a671

Antoni, D., \& Akbar, M. (2019). E-supply chain management value concept for the palm oil industry. Jurnal Sistem Informasi, 15(2), 15-29.

Antoni, D., Fikari, D., \& Akbar, M. (2018). The readiness of palm oil industry in enterprise resource planning. Telkomnika, 16(6), 2692-2702.

Antoni, D., Herdiansyah, M. I., Akbar, M., \& Sumitro, A. (2021). Pengembangan Infrastruktur Jaringan Untuk Meningkatkan Pelayanan Publik di Kota Palembang. JURNAL MEDIA INFORMATIKA BUDIDARMA, 5(4), 1652-1659.

Antoni, D., Jie, F., \& Abareshi, A. (2020). Critical factors in information technology capability for enhancing firm's environmental performance: case of Indonesian ICT sector. International Journal of Agile Systems and Management, 13(2), 159-181.

Borman, R. I., \& Erma, I. (2018). PENGEMBANGAN GAME EDUKASI UNTUK ANAK TAMAN KANAK-KANAK (TK) DENGAN IMPLEMENTASI MODEL PEMBELAJARAN

C. D. Manning, P. Raghavan and H. Schütze, "Evaluation in information retrieval," in An Introduction to Information Retrieval, Cambridge, England, Cambridge University Press, 2009, pp.188-210.

D. Jurafsky and J. H. Martin, "N-Grams," in Speech and Language Processing. 2014.

D. Read and Y. Grushka-Cockayne, "The Similarity Heuristic," Journal of Behavioral Decision Making, no. 24, p. 23-46, 21 June 2011.

Eka Jayanti, W., Eva, M., \& Fahriza, N. (2018). Game Edukasi “Kids Learning” Sebagai Media Pembelajaran Dasar Untuk Anak Usia Dini Berbasis Android. KOPERTIP: Jurnal IlmiahManajemenInformatikaDanKomputer,2(2), 98-104.

https://doi.org/10.32485/kopertip.v2i2.56

Fauzi, F., Dencik, A. B., \& Asiati, D. I. (2019). Metodologi Penelitian untuk manajemen dan akuntansi. Jakarta: Salemba Empat.

Hilaliyah, S. N., Wahyudi, M. H., \& Rohman, M. G. (2017). GAME EDUKASI TEMATIK BERBASIS ANDROID ISSN : 2598-2249 Perkembangan teknologi di

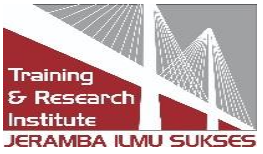


zaman sekarang begitu pesat dan seiring dengan kebutuhan manusia . Maka teknologi turut berkembang untuk tujuan pembelajran dan hiburan . Salah satu bentuknya adalah dalam du. J-Tiies, 1(1).

J. Han and M. Kamber, Data Mining: Concepts and Techniques, Diane Cerra, 2006.

Jurafsky, D. and Martin, J.H., 2018. Speech and language processing (draft). preparation [cited 2020 June 1] Available from: https://web. stanford. edu/ jurafsky/slp3.

Jusuf, H. (2016). Penggunaan Gamifikasi dalam Proses Pembelajaran. Jurnal TICOM, 5(1), 1-6. https://media.neliti.com/media/publications/92772-IDpenggunaan-gamifikasi-dalam-proses- pembe.pdf

Prototype Game Edukasi Materi Sains Menggunakan Pendekatan Kontekstual Di Smp Negeri 4Banjarbaru (Pahmawati dkk, 2021

Read, D. and Grushka-Cockayne, Y., 2011. The similarity heuristic. Journal of Behavioral Decision Making, 24(1), pp.23-46.

Syafnidawaty. (n.d.). METODE WATERFALL. https://raharja.ac.id/2020/04/04/metodewaterfall/ Vitianingsih, A. V. (2016). Game Edukasi Sebagai Media Pembelajaran PAUD. Jurnal INFORM,

VISUALITATION AUDITORY KINESTETHIC (VAK). JIPI (Jurnal Ilmiah Penelitian DanPembelajaran Informatika), 3(1). https://doi.org/10.29100/jipi.v3i1.586

W. H. Gomaa and A. A. Fahmy, "A Survey of Text Similarity Approach," International Journal ofComputer Applications, vol. 68, no. 13, 2013.

Yunanto, A. A., Herumurti, D., \& Kuswardayan, I. (2017). Kecerdasan Buatan Pada Game Edukasi Untuk Pembelajaran Bahasa Inggris Berbasis Pendekatan Heuristik Similaritas. Jurnal Sistem Dan Informatika, 11(2), 16-27. https://www.zenius.net/blog/18040/robot-menggantikan-manusia

\section{Copyrights}

Copyright for this article is retained by the author(s), with first publication rights granted to the journal.

This is an open-access article distributed under the terms and conditions of the Creative Commons Attribution license (http://creativecommons.org/licenses/by/4.0/) 